Original Research

\title{
Preparing $\gamma$-Cyclodextrin-Immobilized Starch and the Study of its Removal Properties to Dyestuff from Wastewater
}

\author{
Zhang Hao ${ }^{1,2}$, Zhang Yi²*, Cheng Bowen ${ }^{1}$, Li Yaxing ${ }^{2}$, Zhou Sheng² \\ ${ }^{1}$ State Key Laboratory of Separation Membranes and Membrane Processes, Tianjin Polytechnic University, \\ Tianjin, P.R. China \\ ${ }^{2}$ School of Textiles, Tianjin Polytechnic University, Tianjin, P.R. China
}

Received: 2 March 2018

Accepted: 17 April 2018

\begin{abstract}
A novel natural polymeric adsorbing material $\gamma$-cyclodextrin immobilized starch (CS$\gamma \mathrm{CD})$ was prepared by introducing host functional molecule $\gamma$-cyclodextrin $(\gamma-\mathrm{CD})$ into starch, using epichlorohydrin (ECH) as a cross-linking agent and sodium hydroxide as a catalyst, via the aqueous-phase synthesis method. The $\gamma$-cyclodextrin content in CS- $\gamma$ CD was up to $8.15 \%$ determined by the bromocresol green (BCG) hyperchromic spectrophotometric method. The structures of CS- $\gamma \mathrm{CD}$ were characterized by infrared spectrum (FT-IR), ${ }^{13} \mathrm{C}$-nuclear magnetic resonance spectrum $\left({ }^{13} \mathrm{C}-\mathrm{NMR}\right)$, scanning electron microscope (SEM), x-ray diffraction (XRD), and gel permeation chromatography (GPC). We investigated the adsorption performances and kinetics of CS- $\gamma \mathrm{CD}$ to three different kinds of dyestuff including methylene blue (MB), methyl purple (MP), and congo red (CR). The results showed the adsorbing capacities of CS- $\gamma \mathrm{CD}$ to three kinds of dyes had obviously increased compared with native starch and diatomite, and the CS- $\gamma$ CD was also found to have a significant advantage in adsorption of macro-molecule dye such as CR over other adsorbing materials. The adsorption behaviors of CS- $\gamma \mathrm{CD}$ on the three dyestuffs could be better described by a Langmuir model $\left(\mathrm{R}^{2}>0.99\right)$, but also had relatively high correlation to Freundlich model. The pseudo second-order model could better describe the adsorption behaviors. The CS- $\gamma \mathrm{CD}$ could be enzymolysised, while its degradation rate was much lower than native starch, which indicated that $\mathrm{CS}-\gamma \mathrm{CD}$ had a relatively higher structural stability and longer service life, these characters could be beneficial for the popularization and application of CS- $\gamma \mathrm{CD}$ in fields of wastewater treatment and environment remediation.
\end{abstract}

Keywords: starch, $\gamma$-cyclodextrin, dye absorption, wastewater treatment, environment remediation

*e-mail: tianjinzhangyi@126.com 


\section{Introduction}

Nowadays, synthetic dyestuff was widely used in industry. Most of the dyes and their metabolites are toxic, and have carcinogenicity and teratogenicity to aquatic organisms and humans. The dyestuff wastewater has characteristics such as high toxicity, high chroma, complicated composition, and super-salinity, and is degradation-resistant, which would cause tremendous influence on the environment. The existing treatments of dye wastewater include precipitation, flocculence, oxidation reduction process, solvent extraction, and the adsorption technique, which has received significant attention for its advantages such as high efficiency, easy operation, and lower cost [1-6]. At present, the adsorbent can be classified into three classes: inorganic, synthetic polymeric, and natural polymeric. The synthetic polymeric adsorbent mainly includes various types of ion-exchange resins and/or other synthetic polymers. Those resins and polymers are basically styrene- or acrylic-based and thus have relatively high physical-chemical stability, and the different functional groups on which could provide them good adsorption capacities on dyes with different structures and electric charges. Those advantages make the synthetic polymeric adsorbents have a relatively broader application than the other two kinds of adsorbents. However, since the manufacturing of the synthetic polymeric adsorbents always requires large quantities of organic solvents, and the wasted adsorbents also have the problem in hard bio-degradation, the production and application processes for those synthetic polymeric adsorbents have been regarded as creating serious pollution fir the environment [7-9]. In comparison, natural polymeric absorbents have the advantages of abundant resources, high adsorption, high selectivity, are degradable and environmentally friendly, and have been regarded as the ideal substitution for inorganic and synthetic polymer adsorbing materials [10-13].

Cyclodextrins (CDs) are cyclic molecules that consist of six to eight glucose molecules: $\alpha-, \beta$-, and $\gamma$-cyclodextrins with six, seven, and eight glucose units, respectively. The cyclodextrins have characteristics such as reducibility, nontoxicity, and hydrolysis resistance. While the main feature of the CDs lies in their peculiar hydrophobic cavum structures. The inner side of the cavum consists of hydrogen atoms and oxygen atoms, which is in the shielding of the $\mathrm{C}-\mathrm{H}$ bonds, while the outside and the top of the cavum consisted of hydrophilic hydroxy groups. This structure makes the cavum have a character of "inner hydrophobic, outer hydrophilic," and could form the inclusion complexes with many kinds of inorganic or organic molecules via the host-guest inclusion reactions $[14,15]$. This feature makes cyclodextrin a potential high-efficiency natural adsorbing material. Among three common cyclodextrins $(\alpha, \beta$, and $\gamma)$, the $\gamma$-CD has the largest cavity dimension (up to about $427 \AA^{3}$, compared with $174 \AA^{3}$ of $\alpha$-CD and $262 \AA^{3}$ of $\beta-C D$ ), thus it is regarded as the greater and wider inclusion capabilities to various organic molecules, and is supposed to be a more effective adsorbing material in dyestuff wastewater treatment. While the water solubility and shaping difficulty of $\gamma$-CD have restricted its application in wastewater treatment $[16,17]$.

Immobilizing $\mathrm{CD}$ onto other high polymers could enhance the physical-chemical stability and mechanical strength of the modified adsorbing material, while keeping the inclusion and adsorption capability of CD. Recently, there have been studies on the immobilization of $\beta$-CD onto other synthetic or natural polymers such as polystyrene, polylactic acid, and chitosan. N Wang et al. had grafted the $\beta$-CD onto $\mathrm{Fe}_{3} \mathrm{O}_{4}$ /poly(glycidyl methacrylate) magnetic nanoparticles, and found the host-guest interactions between cyclodextrin and aromatic molecules had a great contribution to the adsorption to two model environmental pollutants of the modified nanoparticles [18]. L. C. Zhou et al. had prepared the $\beta$-CD-modified chitosan (CS-CD), the CS-CS was used as an adsorbent for the adsorption of 2-chlorophenol (2-CP), 2,4-dichlorophenol (DCP), and 2,4,6-tuichlorophenol (TCP) from aqueous solutions, the results that the introduction of the $\beta-C D$ moiety greatly increased adsorption efficiency [19]. Wang $\mathrm{G}$ et al. had prepared the $\beta$-CD-grafted chitosan (CS-CTS), and the adsorption of acid red R (ARR) in aqueous solution onto CD-CTS was investigated. Compared with chitosan (CTS), the adsorption capacity of CD-CTS for ARR was increased by $20.2 \mathrm{mg} / \mathrm{g}$ after adsorption equilibrium [20]. However, the research on immobilizing modification of $\gamma-\mathrm{CD}$ was very rare [21-24]. Based on the unique advantages of $\gamma$-CD in inclusion and adsorption for organic molecules, in this study, a novel natural polymeric adsorbing material, CS- $\gamma \mathrm{CD}$, was synthesized by immobilizing $\gamma$-CD onto corn starch (CS) macro-molecule by using epichlorohydrin (ECH) as a cross-linking agent. Its adsorption properties to three different kinds of dyes were studied. The results suggest that CS- $\gamma$ CD could become a promising natural polymeric absorbent for dyestuff removal from industrial wastewater.

\section{Materials}

$\gamma$-CD was purchased from Wacker Chemie AG Chemical Reagent Co., Ltd. (Cologne, Germany), and cornstarch was supplied by Qingyang Food Co., Ltd. (Hebei, China). Bromocresol green (BCG), epichlorohydrin (ECH), methylene blue (MB), methyl purple (MP), and Congo red (CR) were purchased from Guangfu Fine Chemical Research Institute (Tianjin, China). All chemical reagents were analytically pure. 


\section{Experimental Procedure}

\section{Preparation of CS- $\gamma \mathrm{CD}$}

$10 \mathrm{~g}$ of cornstarch (CS) was dispersed in $100 \mathrm{~mL}$ of $\mathrm{NaCl}$ solution $\left(\mathrm{w}_{\mathrm{NaCl}} \%=2.5\right), 1.5 \mathrm{~g}$ of $\gamma$-CD was added, the reaction system was adjusted to $\mathrm{pH}=10$ using $20 \% \mathrm{NaOH}$ solution, then $1 \mathrm{~g}$ of ECH was dropwise added within 3 steps during the reaction process. The immobilization reaction was performed at $50^{\circ} \mathrm{C}$ for $6 \mathrm{~h}$, at the end of the reaction, the suspension was cooled down and adjusted to $\mathrm{pH}=6 \sim 7$. The crude product was precipitated by ethyl alcohol and centrifugalized, and then washed by an ethanol-water solution $(65 / 35, v / v)$. Then, after smashing and vacuum drying at $50^{\circ} \mathrm{C}$ for $24 \mathrm{~h}$, the $\gamma$-CD-immobilized starch CS- $\gamma$ CD was obtained.

The $\gamma$-Cyclodextrin content namely immobilization ratio of $\mathrm{CS}-\gamma \mathrm{CD}$ was determined to be $8.15 \%$ by an improved bromocresol green (BCG) hyperchromic spectrophotometric method [25].

\section{Structural Characterization of CS- $\gamma \mathrm{CD}$}

FT-IR spectroscopy was performed on a Nicolet IS50 Fourier transform spectrometer at a resolution of $4 \mathrm{~cm}^{-1}$ over the wave number range of $4000-400 \mathrm{~cm}^{-1}$. The ${ }^{13} \mathrm{C}-\mathrm{NMR}$ determination was performed on a Varian Infinityplus $300 \mathrm{MHz}$ solid nuclear magnetic resonance spectrometer at a spin rate of $8.00 \mathrm{kHz}$ for $5 \mathrm{~h}$. The morphology observation was performed on a Hitachi TM-3030 scanning electron microscope. The XRD analysis was performed on a Rigaku D/MAX-2200 $\mathrm{x}$-ray powder diffractometer at $40 \mathrm{kV}, 150 \mathrm{~mA}$, and a wavelength of $1.54 \AA$. GPC analysis was performed on a Waters 1515 gel permeation chromatographer using $50 \mathrm{mmol} / \mathrm{L} \mathrm{NaCl}$ solution as a mobile phase at an eluant velocity of $1 \mathrm{~mL} / \mathrm{min}$.

\section{Dye Adsorption Experiment of CS- $\gamma \mathrm{CD}$}

To conduct the adsorption experiments, three kinds of dyestuff (methylene blue, methyl purple, and Congo red) were used. A $25 \mathrm{~mL}$ dose of a dye solution $(0.5 \mathrm{mmol} / \mathrm{mL})$ was added to a conical flask. Then, $0.1 \mathrm{~g}$ of the adsorbent was added to the flask. The solution was vibrated at $25^{\circ} \mathrm{C}$ for $1 \mathrm{~h}$ and then filtered to remove the adsorbent. The filtrate was diluted and adjusted to a constant volume, and the concentrations of residual dyestuff were then measured by a UV-2600 $\mathrm{UV}-\mathrm{Vis}$ spectrophotometer at the maximum wavelength of each dyestuff. The amounts of each dye adsorbed onto the adsorbents $\left(\mathrm{Q}_{e}\right.$ in $\left.\mathrm{mmol} / \mathrm{g}\right)$ were calculated from Equation (1):

$$
Q_{e}=\frac{\left(C_{0}-C_{e}\right) V}{m}
$$

...where $\mathrm{C}_{0}$ and $\mathrm{C}_{\mathrm{e}}$ are the initial and equilibrium concentrations of dyestuff in solution $(\mathrm{mmol} / \mathrm{L}), \mathrm{V}$ is the volume of dye solution $(\mathrm{mL})$, and $\mathrm{m}$ is the mass of adsorbent (g).

\section{Degradation Experiment of CS- $\gamma$ CD [26]}

$0.1 \mathrm{~g}$ of sample was put into a conical flask, $3 \mathrm{~mL}$ of $5 \%$ glucoamylase solution, $3 \mathrm{~mL}$ of acetic acid/ sodium acetate buffer solution ( $\mathrm{pH}=4.4)$, and $15 \mathrm{~mL}$ of distilled water was added, the suspension was vibrated at $39^{\circ} \mathrm{C}$ for $1.5 \mathrm{~h}$ and then filtered, and the filtrate was made to constant volume. The total sugar content in the enzymatic hydrolysate was measured by DNS colorimetry method, and the enzyme-degradation rate was calculated by Equation (2):

$$
E H=\frac{C_{s} \times V}{m} \times 100 \%
$$

...where EH is the enzyme-degradation rate of sample $(\%), \mathrm{V}$ is the volume of enzymatic hydrolysate $(\mathrm{mL})$, $\mathrm{C}_{\mathrm{s}}$ is the total sugar content in the enzymatic hydrolysate $(\mathrm{g} / \mathrm{mL})$, and $\mathrm{m}$ is the mass of sample $(\mathrm{g})$.

\section{Results and Discussion}

\section{FT-IR Analysis}

The FT-IR spectra of the CS and CS- $\gamma \mathrm{CD}$ were shown in Fig. 1. The strong absorption band at $3600-3200 \mathrm{~cm}^{-1}$ of $\mathrm{CS}$ was caused by stretching vibration $v_{\mathrm{O}-\mathrm{H}}$ of hydroxyl groups. The band of $\mathrm{C}-\mathrm{H}$ stretching absorption $v_{\text {sC-H }}$ of methylene in CS backbone appeared at $2931 \mathrm{~cm}^{-1}$. The medium intensity absorption at $1630 \mathrm{~cm}^{-1}$ was assigned to the bending vibration $\sigma_{\mathrm{O}-\mathrm{H}}$ of hydroxyl groups. The moderate absorption peaks of CS at 1150, 1120, and $1093 \mathrm{~cm}^{-1}$ were assigned to the stretching vibrations of the hemiacetal linkage $v_{\mathrm{C}-\mathrm{O}-\mathrm{C}}$ and $\mathrm{C}-\mathrm{O}$ bonds $v_{\mathrm{C}-\mathrm{O}}$, respectively [27]. Compared with CS, no new peaks appeared in IR spectra of CS- $\gamma \mathrm{CD}$, since the CS- $\gamma \mathrm{CD}$ and CS were composed with the same constitutional units (anhydroglucose unit AGU). However, many changes were still observable in the spectrum of CS- $\gamma$ CD. The absorption bands of $v_{\mathrm{O}-\mathrm{H}}$ and $\sigma_{\mathrm{O}-\mathrm{H}}$ of $\mathrm{CS}-\gamma \mathrm{CD}$ at $3600-3200 \mathrm{~cm}^{-1}$ and $1630 \mathrm{~cm}^{-1}$ weakened obviously, which might because a part of the hydroxyl groups were consumed during the cross-linking reaction, which led to a decline in the number of $\mathrm{O}-\mathrm{H}$ bonds of $\mathrm{CS}-\gamma \mathrm{CD}$. The stretching vibration $v_{\mathrm{C}-\mathrm{O}-\mathrm{C}}$ near $1150-1120 \mathrm{~cm}^{-1}$ was enhanced, because part of the $\mathrm{O}-\mathrm{H}$ bonds had been transformed into ether linkages after the reaction. Moreover, the vs C-H vibration of CS- $\gamma \mathrm{CD}$ at $2925 \mathrm{~cm}^{-1}$ apparently increased, which was because plenty of methylene groups $-\mathrm{CH}_{2}-$ were introduced to the $\mathrm{CS}-\gamma \mathrm{CD}$ macro-molecule in the reaction with ECH. From 


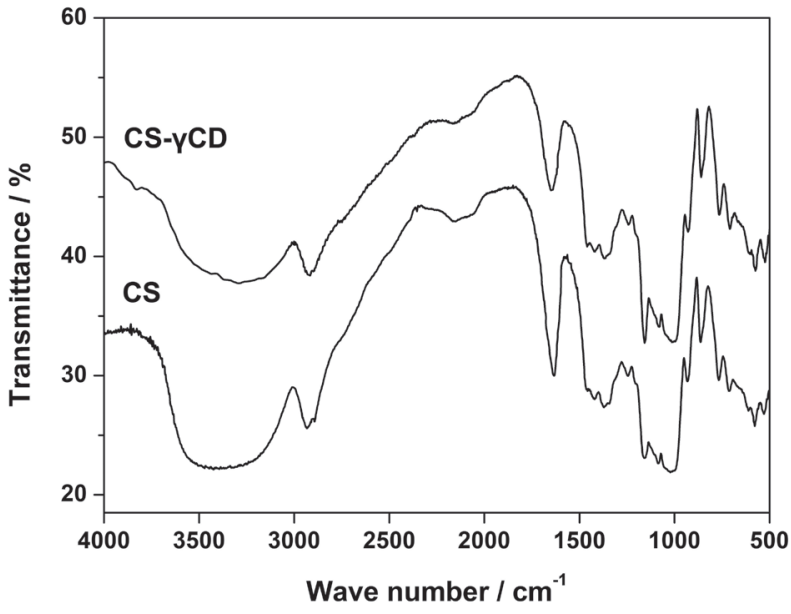

Fig. 1. FT-IR spectra of CS and CS- $\gamma \mathrm{CD}$.

FT-IR analysis it could be known that the $\gamma$-CD was immobilized onto starch macro-molecule via the cross-linking reaction in present of $\mathrm{ECH}$, by the formation of ether linkages [28, 29].

\section{${ }^{13} \mathrm{C}-\mathrm{NMR}$ Analysis}

The ${ }^{13} \mathrm{C}-\mathrm{NMR}$ spectra of the $\mathrm{CS}$ and $\mathrm{CS}-\gamma \mathrm{CD}$ were shown in Fig. 2. The peaks $\mathrm{C} 1 \sim \mathrm{C} 6$ were assigned to the anhydroglucose (AGU), the basic constitutional unit of both starch and cyclodextrin. The chemical shift of $\mathrm{C} 1(\delta=101.5)$ was found at a relatively low field. It was because $\mathrm{Cl}$ was directly connected to two oxygen atoms, which caused a greater deshielding effect. The peak at $\delta 81.9$ was attributed to $\mathrm{C} 4$. The strongest peak near $\delta 71 \sim 74$ was actually due to the overlap of the peaks of $\mathrm{C} 2, \mathrm{C} 3$, and $\mathrm{C} 5$, since those carbon atoms had similar chemical environments [30]. Similar to the IR spectrum, the simple introduction of $\gamma$-CD could not bring about obvious changes in chemical shifts of $\mathrm{C} 1-\mathrm{C} 6$ of $\mathrm{CS}-\gamma \mathrm{CD}$, since the starch

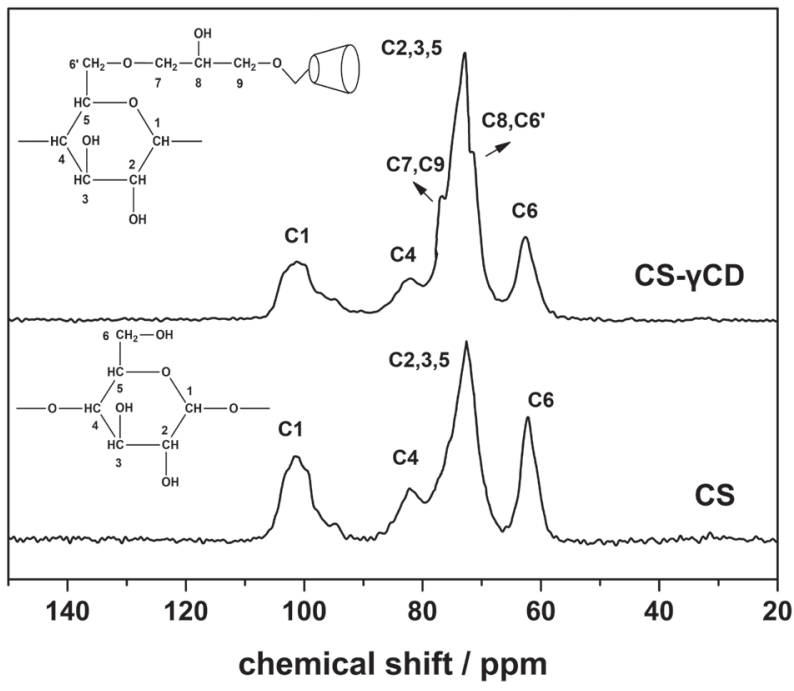

Fig. $2 .{ }^{13} \mathrm{C}-\mathrm{NMR}$ spectra of $\mathrm{CS}$ and $\mathrm{CS}-\gamma \mathrm{CD}$. and cyclodextrin molecules were composed with the same basic constitutional units. While there were still some significant changes to be found in the ${ }^{13} \mathrm{C}-\mathrm{NMR}$ spectrum of CS- $\gamma$ CD. The peak appearing at $\delta 77.8$ was assigned to $\mathrm{C} 7$ and $\mathrm{C}$, while the peak at $\delta 71.3$ was caused by $\mathrm{C} 8$, which belonged to the introduced iso-propanol structure of the $\mathrm{ECH}$ molecule. Those peaks overlapped with peaks of $\mathrm{C} 2, \mathrm{C} 3$, and $\mathrm{C} 5$, and further increased the peak intensity near $\delta 71 \sim 75$. Another obvious change was the decline of C6 signal of $\mathrm{CS}-\gamma \mathrm{CD}$ at $\delta 62.4$, which indicated a significant number of primary hydroxyl groups on $\mathrm{C} 6$ had been replaced by C-O-C bonds. Since the -O- atom had a stronger deshielding effect than $-\mathrm{OH}$ groups, that would make the chemical shift of part of the C6 atoms move to a lower field, and peak of the C6' atoms in the newly formed linkage would overlap with C8 peak near $\delta$ 71.3. In accordance with the result of FT-IR analysis, the $\gamma$-CD combined with starch with ether linkages, and the ${ }^{13} \mathrm{C}-\mathrm{NMR}$ further indicated that the cross-linked reaction mainly occurred on the primary hydroxyl groups on C6 atoms [31].

\section{SEM and XRD Analysis}

From Fig. 3 it could be observed that most native starch granules had a regular shape and smooth
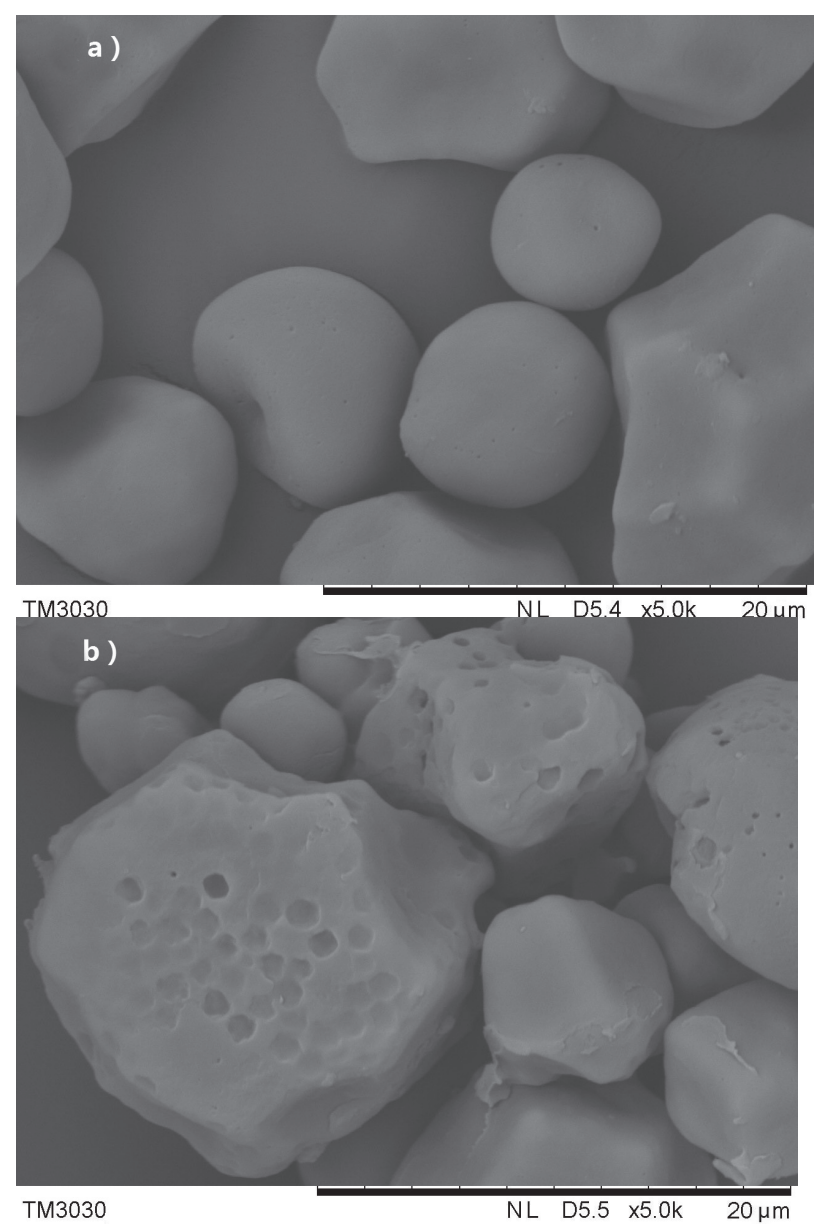

Fig. 3. Scanning electron micro-graphs of CS a) and CS- $\gamma \mathrm{CD} \mathrm{b}$ ). 


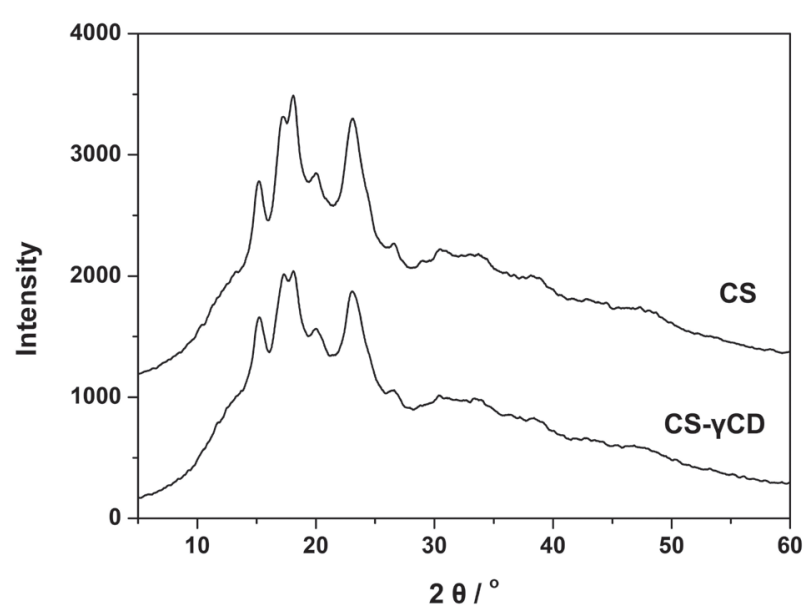

Fig. 4. X-ray diffraction pattern of CS and CS- $\gamma \mathrm{CD}$.

surface. By contrast, the regularity of CS- $\gamma \mathrm{CD}$ granules had declined, and part of the granules showed slight fragmentation, indentation, and the formation of some cavities, those destructive effects could be accounted for in the introduction of cyclodextrin as well as alkali corrosion during the reaction. However, it could also be seen that the CS- $\gamma$ CD granules had generally maintained their integrity, which indicated the above-mentioned "destructive effects" would mainly take place on the surface and in the amorphous region of granules. Fig. 4 showed that CS- $\gamma \mathrm{CD}$ had a similar diffraction pattern to native starch. The crystallinity degree of CS- $\gamma$ CD was calculated at $25.6 \%$, which only had a slight decline compared with the crystallinity degree of CS (29.2\%). The XRD result indicated the crystalline regions of CS- $\gamma \mathrm{CD}$ were basically not corrupted, which was in accordance with the observation in SEM, since the integrity of starch granules was regarded as mainly sustained by their crystalline structures [32]. The XRD and SEM observations had consistently shown that the immobilizing reaction of $\gamma$-CD mostly took place on the surface and in the amorphous regions of starch granules, while their crystalline regions were basically uninfluenced. Thus the $\mathrm{CS}-\gamma \mathrm{CD}$ could generally maintain its integrated crystalline structures, which was beneficial for the application of CS- $\gamma \mathrm{CD}$ as an adsorbent in wastewater treatment, which was because a relatively strong crystalline structure would provide higher physicalchemical, mechanical and biological stability for the natural macro-molecular material [33].

\section{GPC Analysis}

The GPC chromatography of CS and CS- $\gamma \mathrm{CD}$ are shown in Fig. 5, which shows that CS had three main molecular compositions: the macro-molecular component (Ap), the micro-molecular component (Am), and the intermediate (Im), which could be divided by the retention time [34]. The observed basically maintained the elementary structures of native starch,

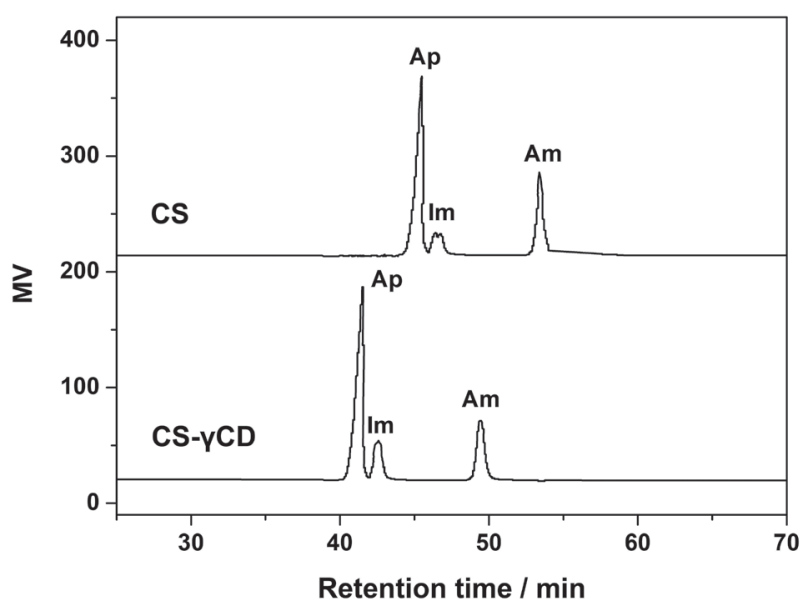

Fig. 5. GPC chromatograms of CS and CS- $\gamma \mathrm{CD}$.

but had an obvious change in peak shape and retention time compared with CS. Firstly, CS- $\gamma$ CD had an declined retention time for each component. More than that, the AP and Im signals in CS- $\gamma$ CD were observed as apparently increased, while the signal of Am was relatively decreased, which indicated that the CS- $\gamma \mathrm{CD}$ had an increase in proportion of macro-molecular and intermediate components. Those changes indicated that CS- $\gamma$ CD not only had an increased molecular weight but also had a more complicated molecular configuration [35]. The macro-molecular structure of CS- $\gamma \mathrm{CD}$ had been found to have a tendency of transforming from a linear from to a cross-linking network. The reasons for the above phenomenon might lie in that, in the course of immobilization reaction, the ECH molecules would not only promote the combination between $\gamma-\mathrm{CD}$ and starch, but also promote the inter and intra molecular crosslinking reactions of CS- $\gamma \mathrm{CD}$ molecules, hence they made their molecular structures become more complicated. While the increase in polymerization degree along with the formation of cross-linked network macromolecule structures of CS- $\gamma \mathrm{CD}$ would help to improve its insolubility, as well as the acid-base, thermal and mechanical stability. The above changes were considered beneficial for the application of CS $-\gamma \mathrm{CD}$ in dye wastewater treatment.

\section{Adsorption Performance Studies}

To systematically investigate the adsorptive properties of CS- $\gamma \mathrm{CD}$, three different kinds of dyestuff were adopted in this study. It could be known from Table 1 and Fig. 6 that methylene blue (MB) was a phenothiazine dye, its matrix was an acridine molecule, the 3,7-dimethylamino substituent groups made it water solvable, and its aqueous solution was alkaline. Methyl purple (MP) was a triarylmethane dye, it had a major structure of three phenyl groups connected with one central carbon atom, and the amidogen substituents on the benzene rings made the MP a basic dyestuff, such as MB. Congo red (CR) was a kind of disazo dyestuff, 
Table 1. Basic characteristics of MB, MP, and CR.

\begin{tabular}{|c|c|c|c|c|}
\hline Dyestuff types & Ionic type & Major functional groups & Molecular Weight & Molecular dimension \\
\hline Methylene blue & Cationic & $-\mathrm{NR}_{2},=\mathrm{NR}_{2}^{+}$ & 319.86 & Smaller \\
\hline Methyl Purple & Cationic & $-\mathrm{NR}_{2},=\mathrm{NR}_{2}^{+}$ & 408.03 & Moderate \\
\hline Congo red & Anionic & $-\mathrm{NH}_{2},-\mathrm{SO}_{3}^{-}$ & 696.68 & Larger \\
\hline
\end{tabular}<smiles></smiles>

Fig. 6. Molecular structures of MB, MP, and CR.

in which the diazo component was the benzidine structure, and the sulfonic groups made CR an acid dyestuff that was negatively charged in its aqueous solution. By comparing the molecular structures of the three dyestuffs, it could be found that the MB, MP, and CR had the lower, moderate, and higher molecular weights and dimensions, respectively. From the view of chemical constitution, MB and MP were two kinds of cationic dyes with $-\mathrm{NR}_{2}$ and $=\mathrm{NR}_{2}^{+}$groups, while CR was a anionic dye with $-\mathrm{NH}_{2}$ and $-\mathrm{SO}_{3}^{-}$groups.

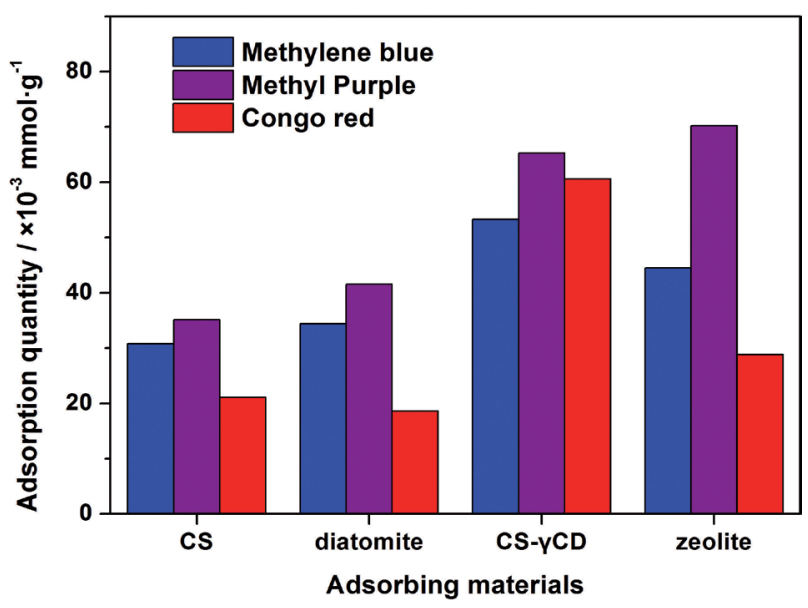

Fig. 7. Adsorption performance of $\mathrm{CS}$, diatomite, $\mathrm{CS}-\gamma \mathrm{CD}$, and zeolite to MB, MP, and CR.
From Fig. 7 it could be learned that CS had a certain extent of adsorption on the three kinds of dyestuffs, which might be because native starch molecules had many -OH groups that could form hydrogen bonds with the polar groups in dye molecules, and there was also Van der Waals forces among the hydrophobic portions of starch backbone and dyestuff molecules [36]. But overall, CS still had the lowest adsorption capacity among all kinds of adsorbents studied in this work. The diatomite and zeolite were two kinds of inorganic adsorbents, the major component of diatomite was $\mathrm{SiO}_{2}$, while zeolite mainly consisted of aluminosilicate. The diatomite was found to have a similar adsorption behavior with $\mathrm{CS}$, since the adsorption of diatomite to dyes was also mostly by its plentiful surface oxygencontaining groups $(-\mathrm{OH},-\mathrm{O}-,-\mathrm{COOH})$. The adsorption of zeolite to dyes was much higher than diatomite and CS, which might owe more to its more developed hole structure and higher specific surface area [37, 38]. More than that, it could be apparently observed that all the adsorbents had poor adsorbability to CR except for CS- $\gamma \mathrm{CD}$. The reason might be that diatomite and CS both had abundant weak acid groups such as hydroxyl and silanol (Si-OH) groups, and the silica tetrahedron structure of zeolite also made its surface negatively charged. As a result, those adsorbents would be more easy to adsorb the cationic dyes with positive charge such as MB and MP, while they might have an electrostatic repulsion to the negatively charged anionic dyes. Moreover, since CR had a relatively large molecular dimension, the greater steric effects from its conjugated system could also interfere with the formation of hydrogen bonds with the adsorbents. All these elements might lead to a relatively low adsorption quantity of CS, diatomite, and zeolite to CR.

Compared with diatomite and CS, the adsorbing capacity of CS- $\gamma \mathrm{CD}$ to three kinds of dyes had obviously increased, although its adsorbability on MP was little lower than zeolite, but they had already closed. Moreover, it could be also found that CS- $\gamma C D$ had a significant enhanced adsorbing capacity to $\mathrm{CR}$ (about 2 3 times over other adsorbents), which might because the $\gamma$-CD had a relatively large hydrophobic cavity (up to $7.2 \sim 8.5 \AA$ in diameter) that could include more kinds of larger-sized organic molecules such as Congo red. For that reason, the immobilization of $\gamma-\mathrm{CD}$ could significantly enhance the adsorption capacity of CS- $\gamma$ CD to CR. Furthermore, the significant increase in adsorption quantity of $\mathrm{CS}-\gamma \mathrm{CD}$ to $\mathrm{CR}$ could also indicate that the adsorption of CS- $\gamma \mathrm{CD}$ to dyes was not 
only by the hydrogen-bond interactions among their polar groups, while the host-guest inclusion effects of CS- $\gamma$ CD hydrophobic cavum toward the dye molecules would also have an important contribution [39, 40].

\section{Adsorption Mechanism Studies}

Adsorption isotherm predicts the amount of adsorbate adsorbed by an adsorbent in terms of the equilibrium concentration of the adsorbate at the constant temperature. The Langmuir and Freundlich models were selected to predict the adsorption isotherm of dyestuff on the adsorbing materials. The Langmuir isotherm model assumed the existence of the homogeneous monolayer surface adsorption on which one dye molecule per binding site was formed without side interactions between the adsorbed molecules [41]. The Langmuir adsorption isotherm can be determined from a linear form of Eq. (3):

$$
\frac{C_{e}}{Q_{e}}=\frac{C_{e}}{Q_{\max }}+\frac{1}{K_{L} Q_{\max }}
$$

...where $\mathrm{Q}_{\mathrm{e}}$ is the amount of dyes adsorbed ( $\left.\mathrm{mg} / \mathrm{g}\right), \mathrm{C}_{\mathrm{e}}$ is the equilibrium concentration of dyes $(\mathrm{mg} / \mathrm{L})$, and $\mathrm{K}_{\mathrm{L}}$ and $\mathrm{Q}_{\max }$ are Langmuir constants.

The Freundlich isotherm model is one of the most common adsorption equations for a solid-liquid system to model the adsorption on heterogeneous surfaces [42]. The Freundlich constants can be calculated in the following linear form of Eq. (4):

$$
\ln Q_{e}=\ln K_{F}+\frac{1}{n} \ln C_{e}
$$

...where $\mathrm{K}_{\mathrm{F}}$ and $\mathrm{n}$ are the Freundlich constants related to the adsorption capacity of the adsorbent $(\mathrm{mg} / \mathrm{g})$ and the energy of adsorption, respectively.

From Table 2 it could be learned that the maximal adsorption capacity $\mathrm{Q}_{\max }$ of native starch to the three dyestuffs were relatively low, and the adsorption behaviors of CS to MB and MP had the high relatively fitting degree $\left(\mathrm{R}^{2}\right)$ to the Langmuir model, which indicated that the adsorption of the MB and MP on the CS could be identified as a chemisorption process. By contrast, the adsorption capacity of CS to CR was not ideal, and its adsorption behavior was found to have a reduced fitting degree to the Langmuir model. The reasons might lie in that the starch was a natural polymer that contains an amount of hydroxyl, and since the hydroxyls were the weakly acidic groups, the CS could be more likely to combine the positively charged cationic dyes such as MB and MP, and the adsorption behaviors of those two dyes could have a higher fitting degree $\left(\mathrm{R}^{2}\right)$ to the Langmuir model. While the $\mathrm{CR}$ was a negatively charged anionic dye, its combining capacity to the starch hydroxyl groups could be weakened. Not only that, but the relatively greater molecular dimension as well as the steric hindrance of CR molecules would also hinder the formation of hydrogen bonds with the adsorbent. Compared with CS, the CS- $\gamma \mathrm{CD}$ had been found to have a significantly improved $\mathrm{Q}_{\max }$ to the three kinds of dyestuff. The correlation coefficients of Langmuir equation of CS- $\gamma \mathrm{CD}$ for three kind of dyes were all above 0.99 , which showed that the adsorption behaviors of $\mathrm{CS}-\gamma \mathrm{CD}$ to the three dyestuffs could be better described by a Langmuir model, which was regarded to be a chemisorption and a monolayer adsorption [43], while it could also be found that each kind of dye had a relatively high correlation coefficient of Freundlich equation $\left(\mathrm{R}^{2}>0.9\right)$. The results indicated the adsorption of CS- $\gamma$ CD to the three dyestuffs was not a simple chemisorption process, and the combinations with adsorbent and dye molecules could be not only via the hydrogen-bond interactions among their polar groups, while the host-guest inclusion effects of $\gamma-C D$ non-polar cavums to dye molecules could also play an important role. While another interesting point was that MP and CR had the relatively higher Freundlich model fitting $\left(\mathrm{R}^{2}\right)$ compared with micro-molecular dye MB. It seemed that with the increase in dyes molecular dimension, the adsorption of dyestuff on CS- $\gamma \mathrm{CD}$ had become more and more a physical absorption process, which indicated that the inclusion associations between $\gamma$-CD cavums and dye molecules would play an increasingly important role [44]. The results could explain the phenomenon that $\mathrm{CS}-\gamma \mathrm{CD}$ had a significant

Table 2. Langmuir and Freundlich equation fitting parameters and linearly dependent coefficients of CS- $\gamma$ CD to MB, MP, and CR.

\begin{tabular}{|c|c|c|c|c|c|c|c|c|c|}
\hline \multirow{3}{*}{ Adsorbent } & \multirow{2}{*}{$\begin{array}{c}\text { Dye } \\
\text { types }\end{array}$} & \multicolumn{4}{|c}{ Langmuir model } & \multicolumn{3}{c|}{ Freundlich model } \\
\cline { 3 - 11 } & Adsorption isotherms & $\begin{array}{c}\mathrm{Q}_{\max } \\
\mathrm{mg} / \mathrm{g}\end{array}$ & $\begin{array}{c}\mathrm{K}_{\mathrm{L}} \\
\mathrm{L} / \mathrm{mg}\end{array}$ & $\mathrm{R}^{2}$ & Adsorption isotherms & $\mathrm{K}_{\mathrm{F}}$ & $\mathrm{n}$ & $\mathrm{R}^{2}$ \\
\hline \multirow{3}{*}{$\mathrm{CS}$} & $\mathrm{MB}$ & $\mathrm{y}=0.072 \mathrm{x}+0.391$ & 13.98 & 0.182 & 0.998 & $\mathrm{y}=0.281 \mathrm{x}+1.419$ & 4.132 & 3.566 & 0.903 \\
\cline { 2 - 12 } & $\mathrm{MP}$ & $\mathrm{y}=0.047 \mathrm{x}+0.792$ & 21.50 & 0.059 & 0.999 & $\mathrm{y}=0.384 \mathrm{x}+1.204$ & 3.332 & 2.601 & 0.959 \\
\cline { 2 - 12 } & $\mathrm{CR}$ & $\mathrm{y}=0.032 \mathrm{x}+6.43$ & 30.96 & 0.005 & 0.950 & $\mathrm{y}=0.649 \mathrm{x}+0.697$ & 2.007 & 1.541 & 0.967 \\
\hline \multirow{3}{*}{$\mathrm{CS}-\gamma \mathrm{CD}$} & $\mathrm{MB}$ & $\mathrm{y}=0.052 \mathrm{x}+0.614$ & 19.34 & 0.084 & 0.995 & $\mathrm{y}=0.385 \mathrm{x}+1.235$ & 3.44 & 2.59 & 0.929 \\
\cline { 2 - 12 } & $\mathrm{MP}$ & $\mathrm{y}=0.034 \mathrm{x}+0.312$ & 29.15 & 0.109 & 0.992 & $\mathrm{y}=0.372 \mathrm{x}+1.793$ & 6.01 & 2.69 & 0.973 \\
\cline { 2 - 11 } & $\mathrm{CR}$ & $\mathrm{y}=0.015 \mathrm{x}+1.304$ & 64.94 & 0.012 & 0.990 & $\mathrm{y}=0.635 \mathrm{x}+0.632$ & 1.88 & 1.58 & 0.971 \\
\hline
\end{tabular}




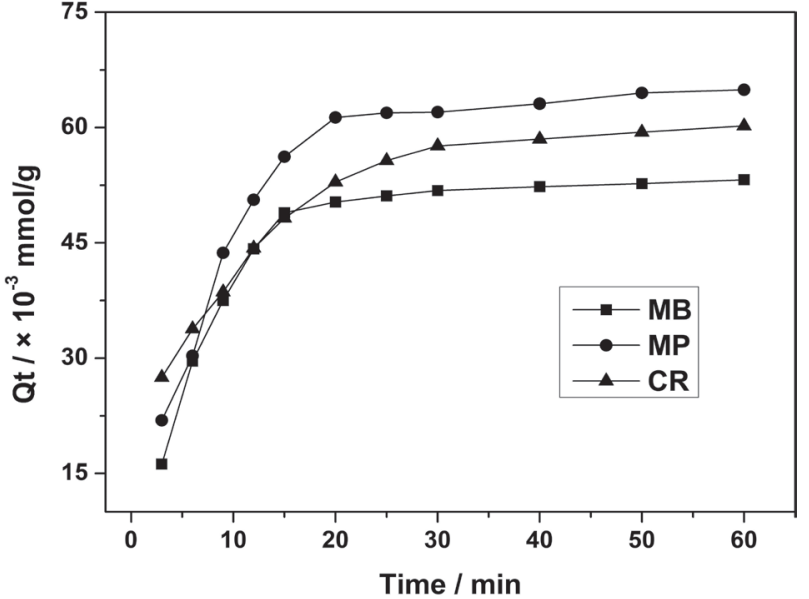

Fig. 8. Isotherms for MB, MP, and CR adsorption on CS- $\gamma \mathrm{CD}$.

advantage in adsorbing macro-molecule dyes such as CR compared with other adsorbents.

\section{Adsorption Isotherms and Kinetics Studies}

The adsorption isotherms of the CS- $\gamma \mathrm{CD}$ for $\mathrm{MB}$, $\mathrm{MP}$, and $\mathrm{CR}$ are shown in Fig. 8. The adsorption rates of the CS $-\gamma \mathrm{CD}$ for the three dyestuffs increased rapidly, and then gradually decreased over 20-30 min and tended to reach adsorption equilibrium after $40 \mathrm{~min}$.

The adsorption kinetics describe the adsorption behavior and rate at different times. Pseudo first- and second-order kinetics equations are the most commonly used models. In a pseudo first-order kinetic model, the process of the adsorbate reaching the adsorbent surface is considered to be controlled by a diffusion step, and there is only one type of binding site on the surface of the adsorbent. The pseudo second-order model is based on the assumption that the adsorption process involves the transfer or sharing electron pairs between the adsorbate and the adsorbent. Namely, the adsorption kinetics are controlled not by diffusion steps but by a chemical action such as ionic, covalent, or coordinate bonding. The first-order rate equation may be represented as Eq. (5):

$$
\ln \left(q_{e}-q_{t}\right)=\ln q e-k_{1} t
$$

Similarly, the second-order rate equation was given by Eq. (6):

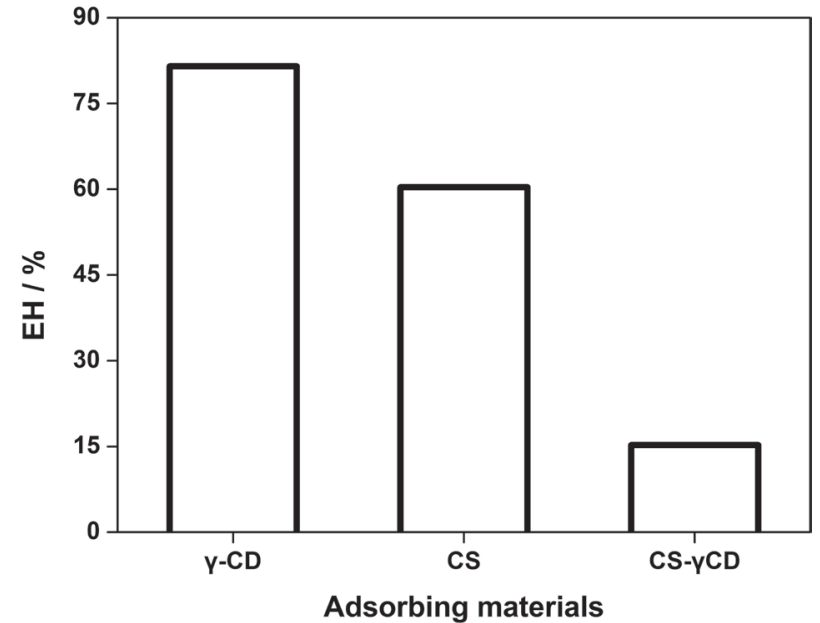

Fig. 9. Enzymatic hydrolysis rate (EH) of $\gamma-\mathrm{CD}, \mathrm{CS}$, and CS- $\gamma$ CD.

$$
\frac{t}{q_{t}}=\frac{1}{k_{2} q_{e}{ }^{2}}+\frac{t}{q_{e}}
$$

...where $\mathrm{q}_{\mathrm{e}}$ and $\mathrm{q}_{\mathrm{t}}$ were the amounts of dyestuff adsorbed at equilibrium and at time $\mathrm{t}$ in $\mathrm{mg} / \mathrm{g}$, and $\mathrm{k}_{1}$ and $\mathrm{k}_{2}$ were rate constants in $\mathrm{min}^{-1}$ and $\mathrm{g} / \mathrm{mg} \cdot \mathrm{min}$, respectively [45].

Table 3 shows that that pseudo second-order model could better describe the adsorption behaviors of CS$\gamma \mathrm{CD}$ to $\mathrm{MB}$, MP, and $\mathrm{CR}$, and the adsorption could be regarded as a chemisorption dominant process [46]. Furthermore, the CR was found to have an increased fitting degree $\left(\mathrm{R}^{2}\right)$ to the pseudo first-order model, which indicated that the CS- $\gamma \mathrm{CD}$ would have a more complicated adsorption behavior for CR, where the hostguest inclusion effects of $\gamma$-CD non-polar cavums to CR molecules could play a more important role compared with two other kinds of cationic dyes. The results of the adsorption kinetic study were also in accordance with the analysis of the isothermal adsorption models.

\section{Degradation Performance Studies}

Since the degradation of microorganisms on natural materials was known primarily through enzymatic actions, the enzyme hydrolysis method was adopted in the degradability quantitative analysis of CS- $\gamma \mathrm{CD}$ in this study. Fig. 9 showed that $\gamma-\mathrm{CD}$

Table 3. Kinetic parameters of CS- $\gamma$ CD to MB, MP, and CR at $298 \mathrm{~K}$.

\begin{tabular}{|c|c|c|c|c|c|c|c|c|}
\hline \multirow{2}{*}{$\begin{array}{c}\text { Dye } \\
\text { types }\end{array}$} & \multicolumn{4}{|c|}{ Pseudo first-order model } & \multicolumn{4}{c|}{ Pseudo second-order model } \\
\cline { 2 - 10 } & Adsorption isotherms & $\begin{array}{c}\mathrm{K}_{1} \\
\mathrm{~min}^{-1}\end{array}$ & $\begin{array}{c}\mathrm{Q}_{\text {e-exp }} \\
\mathrm{mg} / \mathrm{g}\end{array}$ & $\mathrm{R}^{2}$ & Adsorption isotherms & $\begin{array}{c}\mathrm{K}_{2} \\
\mathrm{~g} \cdot \mathrm{mg}^{-1} \cdot \mathrm{min}^{-1}\end{array}$ & $\begin{array}{c}\mathrm{Q}_{\text {e-cal }} \\
\mathrm{mg} / \mathrm{g}\end{array}$ & $\mathrm{R}^{2}$ \\
\hline MB & $\mathrm{y}=1.940-0.055 \mathrm{x}$ & 0.055 & 6.960 & 0.832 & $\mathrm{y}=0.054 \mathrm{x}+0.255$ & 0.0112 & 18.692 & 0.994 \\
\hline MP & $\mathrm{y}=2.584-0.061 \mathrm{x}$ & 0.061 & 13.247 & 0.894 & $\mathrm{y}=0.034 \mathrm{x}+0.191$ & 0.0061 & 29.498 & 0.993 \\
\hline $\mathrm{CR}$ & $\mathrm{y}=3.137-0.058 \mathrm{x}$ & 0.058 & 23.035 & 0.962 & $\mathrm{y}=0.022 \mathrm{x}+0.114$ & 0.0042 & 45.871 & 0.998 \\
\hline
\end{tabular}


had the highest enzymatic hydrolysis rate, after the enzymatic hydrolysis reaction of $1.5 \mathrm{~h}$ the EH was up to $81.52 \%$. Since $\gamma$-CD was a cyclic-oligosaccharide composed of 8 glucopyranose units, it seemed very easy to hydrolyze the function of glucoamylase. The native corn starch was also easy to affect by the enzymatic hydrolysis actions, the EH of CS had reached $60.37 \%$. The CS- $\gamma$ CD had been found have a significant decrease in enzymatic hydrolysis rate $(\mathrm{EH}=15.25 \%)$ compared with $\gamma$-CD and CS. The reason could be that after the $\mathrm{ECH}$ cross-linking reaction, part of the hydroxyl groups were transformed into more stable ether linkages (- O-) by inter-molecular dehydration, which would not only increase the polymerization degree of CS- $\gamma \mathrm{CD}$ but also transform its macro-molecular configuration from a simpler chain to a more complicated network structure. Hence the complex molecular structure of CS- $\gamma$ CD could produce more steric-hinerance and provide more protection for the glycosidic bonds from the attack of enzymes, and as a result the enzyme stability of CS- $\gamma \mathrm{CD}$ had been improved to a certain extent [47].

One side, since the CS- $\gamma \mathrm{CD}$ could be hydrolyzed by enzyme, it could be classified as a bio-degradable natural polymeric material; on the other side, $\mathrm{CS}-\gamma \mathrm{CD}$ had a much lower enzymolysis rate compared with native starch, which indicated that the CS- $\gamma \mathrm{CD}$ had a certain resistance to the decomposition of microorganisms and could be able to maintain its structural stability in a relatively long period of time. This characteristic would be helpful for CS $-\gamma \mathrm{CD}$ to overcome the existing defects of natural polymer materials such as fast degradation, structural instability, and short service life, thus making the CS- $\gamma \mathrm{CD}$ a highly efficient natural polymeric adsorbent and have a more widespread application in dyestuff wastewater treatment.

\section{Conclusion}

(1) In this study a novel natural polymeric adsorbing material CS- $\gamma$ CD was synthesized by using native cornstarch as a raw material and $\gamma$-cyclodextrin as a modifier. The IR and ${ }^{13} \mathrm{C}-\mathrm{NMR}$ spectra showed that $\gamma$-CD had been introduced into starch by the formation of ether linkages in the presence of ECH. The SEM and XRD observation showed that the immobilization of $\gamma-\mathrm{CD}$ took place mostly on the surface and in the amorphous region of starch granules. The GPC analysis showed that the CS- $\gamma \mathrm{CD}$ had not only an increased molecular weight but also a more complicated molecular configuration compared with CS.

(2) The adsorbing performances of CS- $\gamma \mathrm{CD}$ on $\mathrm{MB}, \mathrm{MP}$, and $\mathrm{CR}$ were obviously improved compared with $\mathrm{CS}$ and diatomite, and CS- $\gamma$ CD was also found to have a significant enhanced adsorbing capacity to $\mathrm{CR}$. The adsorption behaviors of $\mathrm{CS}-\gamma \mathrm{CD}$ on the three dyestuffs could be better described by a Langmuir model, but also had a relatively high correlation to the Freundlich model, which indicated that the adsorption of CS- $\gamma \mathrm{CD}$ to dyestuff was not a simple chemisorption process. The pseudo second-order model could better describe the adsorption behaviors. The combination with CS $-\gamma \mathrm{CD}$ and dye molecules was regarded not only via the hydrogen-bond interactions, and the host-guest inclusion effects of $\gamma$-CD non-polar cavums to dye molecules could also play an important role.

(3) The CS- $\gamma \mathrm{CD}$ could be hydrolyzed by enzyme, but its degradation rate was much lower than $\mathrm{CS}$ and $\gamma-C D$, meaning that CS- $\gamma C D$ had a certain extent of resistance to bio-degradation. The result indicated CS- $\gamma$ CD would have a much higher structural stability and much longer service life compared with native starch, which would be beneficial for the industrial application of $\mathrm{CS}-\gamma \mathrm{CD}$ in dyestuff wastewater treatment.

\section{Acknowledgements}

This work was funded by the National Natural Science Foundation of China (No. 51503147), the National Modern Agricultural Technology System Special Projects (No. CARS-43-E-2), the National Key R\&D Program of China (No. 2016YFB0303300), and the National Undergraduate Innovation Program (No. 2016100580).

\section{Conflict of Interest}

The authors declare no conflict of interest.

\section{References}

1. KHAN H., AHMAD N., YASAR A., SHAHID R. Advanced oxidative decolorization of Red Cl-5B: effects of dye concentration, process optimization and reaction kinetics. Polish Journal of Environmental Studies, 19 (1), 83, 2010.

2. OZYONAR F., KARAGOZOGLU B. Operating cost analysis and treatment of domestic wastewater by electrocoagulation using aluminum electrodes. Polish Journal of Environmental Studies, 20 (1), 173, 2011.

3. KALKAN E. Experimental Study to Remediate Acid Fuchsin Dye Using Laccase-Modified Zeolite from Aqueous Solutions. Polish Journal of Environmental Studies, 24 (1), 115, 2015.

4. MAHMOODI N.M., HAYATI B., ARAMI M., LAN C. Adsorption of textile dyes on Pine Cone, from colored wastewater: Kinetic, equilibrium and thermodynamic studies. Desalination, 268 (1), 117, 2011.

5. GE P., LI F. Kinetics and Thermodynamics of Heavy Metal $\mathrm{Cu}$ (II) Adsorption on Mesoporous Silicates. Polish Journal of Environmental Studies, 20 (2), 339, 2011.

6. GIL A., ASSIS F.C.C., ALBENIZ S., KORILI S.A. Removal of dyes from wastewaters by adsorption on 
pillared clays. Chemical Engineering Journal, 168 (3), 1032, 2011.

7. MATSUOKA Y, YAMAOKA K. Film Dichroism. II. Linearly-polarized Absorption Spectra of Acridine Dyes in the Stretched Poly (vinyl alcohol) Films[J]. Bulletin of the Chemical Society of Japan, 52 (11), 3163, 2006.

8. CAN H.K., KIRCI B., KAVLAK S., GUNER A. Removal of some textile dyes from aqueous solutions by poly $(\mathrm{N}-$ vinyl-2-pyrrolidone) and poly(N-vinyl-2-pyrrolidone)/ $\mathrm{K}_{2} \mathrm{~S}_{2} \mathrm{O}_{8}$ hydrogels $[\mathrm{J}]$. Radiation Physics \& Chemistry, 68 (5), 811, 2003.

9. YAVUZ E., BAYRAMOĞLU G., ARICA M.Y., SENKAL B.F. Preparation of poly (acrylic acid) containing core-shell type resin for removal of basic dyes[J]. Journal of Chemical Technology \& Biotechnology, 86 (5), 699, 2011.

10. TRAVLOU N.A., KYZAS G.Z., LAZARIDIS N.K., DELIYANNI E.A. Graphite oxide/chitosan composite for reactive dye removal. Chemical Engineering Journal, 217 (1), 256, 2013.

11. JUANG R., TSENG R., WU F., LEE S.H. Adsorption behavior of reactive dyes from aqueous solutions on chitosan. Journal of Chemical Technology \& Biotechnology Biotechnology, 70 (4), 391, 2010.

12. NGAH W.S.W, TEONG L.C., HANAFIAH M.A.K.M. Adsorption of dyes and heavy metal ions by chitosan composites: A review. Carbohydrate Polymers, 83 (4), 1446, 2011

13. JANAKI V., VIJAYARAGHAVAN K., OH B.T., LEE K.J., MUTHUCHELIAN K., RAMASAMY A.K., SERALATHAN K.K. Starch/polyaniline nanocomposite for enhanced removal of reactive dyes from synthetic effluent. Carbohydrate Polymers, 90 (4), 1437, 2012.

14. SANTOS E.H., KAMIMURA J.A., HILL L.E., GOMES C.L. Characterization of carvacrol beta-cyclodextrin inclusion complexes as delivery systems for antibacterial and antioxidant applications[J]. LWT - Food Science and Technology, 60 (1), 583, 2015.

15. DONG C., YE Y., QIAN L., ZHAO G. Antibacterial modification of cellulose fibers by grafting $\beta$-cyclodextrin and inclusion with ciprofloxacin[J]. Cellulose, 21 (3), 1921, 2014.

16. LIU B., LI H., XU X., LV N, SINGH V., STODDART J. F., YORK P, XU X., GREF R., ZHANG J.W. Optimized synthesis and crystalline stability of $\gamma$-cyclodextrin metalorganic frameworks for drug adsorption. International Journal of Pharmaceutics, 514 (1), 212, 2016.

17. INOUE Y., SUZUKI K., EZAWA T., MURATA I., YOKOTA M., TOKUDOME Y., KANAMOTO I. Examination of the physicochemical properties of caffeic acid complexed WITH $\Gamma$-CYCLODEXTRIN. JOURNAL OF INCLUSION PHENOMENA \& MACROCYCLIC CHEMISTRY, 83 (3-4), 289, 2015.

18. WANG X., ZHOU Z., JING G. Synthesis of $\mathrm{Fe}_{3} \mathrm{O}_{4}$ poly(styrene-glycidyl methacrylate) magnetic porous microspheres and application in the immobilization of Klebsiella sp. FD-3 to reduce Fe(III)EDTA in a NO(x) scrubbing solution[J]. Bioresour Technol, 130 (2), 750, 2013.

19. ZHOU L.C., JIAN-MEI L.I. Kinetics and Thermodynamics of Adsorption of Chlorophenols onto $\beta$-Cyclodextrin Modified Chitosan[J]. Acta Physico-Chimica Sinica, 28 (7), 1615, 2012 (8)

20. WANG G., ZHOU Y., CHAI X., ZHENG C. L., ZHAO H.X., ZHOU X.B. Adsorption behavior of azo dye acid red $\mathrm{r}$ in aqueous solution onto $\beta$-cyclodextrin-grafted
chitosan[J]. Fresenius Environmental Bulletin, 19 (5), 811, 2010.

21. DEDAI L.U., LIQIANG YANG, TIANHONG ZHOU, LEI Z.P. Synthesis, characterization and properties of biodegradable polylactic acid- $\beta$-cyclodextrin cross-linked copolymer microgels. European Polymer Journal, 44 (7), 2140, 2008

22. AND R.A., RINAUDO M. New Supramolecular Assemblies of a Cyclodextrin-Grafted Chitosan through Specific Complexation. Macromolecules, 35 (21), 7955, 2008.

23. JIAXI H., KAIJUN X., ZHONGJIE D., ZOH W., ZHANG C. $\beta$-Cyclodextrin functionalized polystyrene porous monoliths for separating phenol from wastewater. Carbohydrate Polymers, 120 (20), 85, 2015.

24. LÓPEZ-DE-DICASTILLO C., GALLUR M., CATALÁ R., GAVARA R., HERNANDEZ M.P. Immobilization of $\beta$-cyclodextrin in ethylene-vinyl alcohol copolymer for active food packaging applications. Journal of Membrane Science, 353 (1), 184, 2010.

25. LIU H., ZHENG-BIAO G.U., HONG Y., LI Z.F. Hyperchromic Spectrophotometric Determination of $\gamma$-Cyclodextrin with Bromocresol Green. Journal of Food Science \& Biotechnology, 28 (4), 451, 2009.

26. XIANG-JUN Q.I., GOU J.X., HAN X.J., YAN B. Study on Measuring Reducing Sugar by DNS Reagent. Journal of Cellulose Science \& Technology, 12 (3), 17, 2004.

27. DEMIATE I.M., DUPUY N., HUVENNE J.P., CEREDA M.P., WOSIACKI G. Relationship between baking behavior of modified cassava starches and starch chemical structure determined by FTIR spectroscopy. Carbohydrate Polymers, 42 (2), 149, 2000.

28. DELVAL F., CRINI G., BERTINI S., TORRI G. Preparation, characterization and sorption properties of crosslinked starch-based exchangers. Carbohydrate Polymers, 60 (1), 67, 2005.

29. JYOTHI A.N., MOORTHY S.N., RAJASEKHARAN K.N. Effect of Cross-linking with Epichlorohydrin on the Properties of Cassava (Manihot esculenta Crantz) Starch. Starch/Stärke, 58 (6), 292, 2010.

30. LIAN X., WANG C., ZHANG K., LI L. The retrogradation properties of glutinous rice and buckwheat starches as observed with FT-IR, ${ }^{13} \mathrm{C}$ NMR and DSC. International Journal of Biological Macromolecules, 64 (3), 288, 2014.

31. THÉRIENAUBIN H., JANVIER F., BAILLE W.E., ZHOU X.X., MARCHESSAULT RH. Study of hydration of cross-linked high amylose starch by solid state ${ }^{13} \mathrm{C}$ NMR spectroscopy. Carbohydrate Research, 342 (11), $1525,2007$.

32. ZHANG H., LIU B., QIU Y., FAN J.F., YU S.J. Microwave-assisted synthesis and characterization of acetylated corn starch. Starch/Stärke, 66 (5-6), 515, 2013.

33. MANDAL B., RAY S.K. Synthesis, characterization, swelling and dye adsorption properties of starch incorporated acrylic gels. International Journal of Biological Macromolecules, 81 (11), 847, 2015.

34. QIAOYU L., DIAO S., XIONG S., ZHANG S.H. GPC Analysis of Rice Starches and Their Components from Different Rice Species. Food Science, 24 (3), 105, 2003.

35. YU W., TAN X., ZOU W., HU Z.X., FOX G.P., GIDLEY M.J., GILBERT R.G. Relationships between protein content, starch molecular structure and grain size in barley. Carbohydrate Polymers, 155 (8), 271, 2017.

36. XU S., WANG J., WU R., WANG J.D., LI H. Adsorption behaviors of acid and basic dyes on crosslinked 
amphoteric starch. Chemical Engineering Journal, 117 (2), 161, 2006.

37. ERDEM E., CÖLGEÇEN G., DONAT R. The removal of textile dyes by diatomite earth. Journal of Colloid \& Interface Science, 282 (2), 314, 2005.

38. ALPAT S.K., ÖZGE ÖZBAYRAK, SENOL ALPAT, AKCAY $H$. The adsorption kinetics and removal of cationic dye, Toluidine Blue $\mathrm{O}$, from aqueous solution with Turkish zeolite. Journal of Hazardous Materials, 151 (1), 213, 2008.

39. SHEN H.M., ZHU G.Y., YU W.B., WU H.K. Surface immobilization of $\beta$-cyclodextrin on hybrid silica and its fast-adsorption performance to p-nitrophenol from aqueous phase. Rsc Advances, 5(103), 84410, 2015.

40. KYZAS G.Z., LAZARIDIS N.K., BIKIARIS D.N. Optimization of chitosan and $\beta$-cyclodextrin molecularly imprinted polymer synthesis for dye adsorption. Carbohydrate Polymers, 91 (1), 198, 2013.

41. PUNRATTANASIN P., SARIEM P. Adsorption of Copper, Zinc, and Nickel using Loess as Adsorbent by Column Studies. Polish Journal of Environmental Studies, 24 (3), 1259, 2015.

42. WANG T., ZHANG W., LU X. Preparation and Cu (II) Adsorption Characteristics of Carboxymethyl Cross-
Linked Sewage Sludge. Polish Journal of Environmental Studies, 25 (2), 805, 2016.

43. ARMAGAN B., TOPRAK F. Optimum Isotherm Parameters for Reactive Azo Dye onto Pistachio Nut Shells: Comparison of Linear and Non-Linear Methods. Polish Journal of Environmental Studies, 22 (4), 1007, 2013.

44. CRINI G. Kinetic, equilibrium studies on the removal of cationic dyes from aqueous solution by adsorption onto a cyclodextrin polymer. Dye Pigment. Dyes \& Pigments, 77 (2), 415, 2008.

45. ZHANG Y., ZHANG H., YANG W. Rabbit Protein Adsorption Properties of Copper (II) Ion-Polluted Soil[J]. Polish Journal of Environmental Studies, 24 (5), 2015.

46. ZHANG Y., ZHANG H., LIU Y., DING C.K. Chelating Ability and Microbial Stability of an 1 -Arginine-Modified Chitosan-Based Environmental Remediation Material[J]. Journal of Polymers \& the Environment, 26 (3), 885, 2018.

47. KIM M., LEE S.J. Characteristics of crosslinked potato starch and starch-filled linear low-density polyethylene films. Carbohydrate Polymers, 50 (4), 331, 2002. 
